\title{
Dapagliflozin improves muscle insulin sensitivity but enhances endogenous glucose production
}

\author{
Aurora Merovci, Carolina Solis-Herrera, Giuseppe Daniele, Roy Eldor, \\ Teresa Vanessa Fiorentino, Devjit Tripathy, Juan Xiong, Zandra Perez, \\ Luke Norton, Muhammad A. Abdul-Ghani, and Ralph A. DeFronzo \\ Diabetes Division, University of Texas Health Science Center, San Antonio, Texas, USA.
}

\begin{abstract}
Chronic hyperglycemia impairs insulin action, resulting in glucotoxicity, which can be ameliorated in animal models by inducing glucosuria with renal glucose transport inhibitors. Here, we examined whether reduction of plasma glucose with a sodium-glucose cotransporter 2 (SGLT2) inhibitor could improve insulin-mediated tissue glucose disposal in patients with type 2 diabetes. Eighteen diabetic men were randomized to receive either dapagliflozin $(n=12)$ or placebo $(n=6)$ for 2 weeks. We measured insulin-mediated whole body glucose uptake and endogenous glucose production (EGP) at baseline and 2 weeks after treatment using the euglycemic hyperinsulinemic clamp technique. Dapagliflozin treatment induced glucosuria and markedly lowered fasting plasma glucose. Insulin-mediated tissue glucose disposal increased by approximately $18 \%$ after 2 weeks of dapagliflozin treatment, while placebo-treated subjects had no change in insulin sensitivity. Surprisingly, following dapagliflozin treatment, EGP increased substantially and was accompanied by an increase in fasting plasma glucagon concentration. Together, our data indicate that reduction of plasma glucose with an agent that works specifically on the kidney to induce glucosuria improves muscle insulin sensitivity. However, glucosuria induction following SGLT2 inhibition is associated with a paradoxical increase in EGP. These results provide support for the glucotoxicity hypothesis, which suggests that chronic hyperglycemia impairs insulin action in individuals with type 2 diabetes.
\end{abstract}

\section{Introduction}

Hyperglycemia is a sine qua non in type 2 diabetes mellitus (T2DM), and it is the principle factor responsible for the development of diabetic microvascular complications (1). Chronic hyperglycemia, i.e., glucotoxicity, also worsens the 2 core defects, insulin resistance and $\beta$ cell dysfunction, that are characteristic of T2DM (2). Studies in experimental animals (2-6) using the insulin clamp technique have demonstrated that even small persistent increases in the plasma glucose concentration impair insulin-mediated glucose disposal. Moreover, correction of the hyperglycemia restores normal tissue responsiveness to insulin $(3,5)$. Although the glucotoxic effect of hyperglycemia is well established in experimental animals, evidence for the detrimental effect of chronic hyperglycemia in individuals with T2DM is not well established. In individuals with normal glucose tolerance (NGT), a modest elevation in day-long plasma glucose concentration for 24 hours causes a $29 \%$ decrease in whole body insulin-mediated glucose disposal (7), and similar observations have been made in individuals with type 1 diabetes (8). In subjects with NGT, we have shown that chronic (3 days) physiologic hyperglycemia markedly impairs insulin-stimulated nonoxidative glucose disposal (which primarily represents glycogen synthesis), without inhibiting insulin-stimulated glucose oxidation (9). Conversely, lowering the plasma glucose concentra-

Conflict of interest: Ralph A. DeFronzo is a member of the advisory boards of Takeda, Bristol-Myers Squibb, Janssen, Boehringer Ingelheim, Novo Nordisk, Lexicon, and Amylin. Ralph A. DeFronzo is a member of the speakers' bureau of Novo Nordisk, Amylin, Bristol-Myers Squibb, and Janssen. Ralph A. DeFronzo has grant support from Takeda, Amylin, and Bristol-Myers Squibb. As a staff physician, Ralph A. DeFronzo receives salary support from the VA Health Care System.

Citation for this article: J Clin Invest. 2014;124(2):509-514. doi:10.1172/JCI70704. tion with insulin therapy in individuals with T2DM significantly improves insulin-mediated glucose disposal $(10,11)$. However, these latter studies are difficult to interpret, since insulin therapy also exerts other metabolic effects, e.g., reduction in plasma free fatty acid concentration (12), which profoundly affect insulin sensitivity independent of changes in plasma glucose concentration (13). Moreover, chronic insulin infusion to create physiologic hyperinsulinemia causes insulin resistance in subjects with NGT (14). Thus, factors other than correction of hyperglycemia could account for the improvement in insulin action following insulin therapy. To examine the impact of chronic hyperglycemia on insulin sensitivity in individuals with T2DM, we examined the effect of lowering the plasma glucose concentration on whole body insulin sensitivity by inhibiting renal sodium-glucose cotransport with dapagliflozin (15) using the insulin clamp technique. This strategy lowers the plasma glucose concentration without altering other metabolic processes. Our results provide the first definitive evidence in humans for the glucotoxicity hypothesis.

\section{Results}

Subject characteristics. Twelve subjects were randomized to the dapagliflozin arm and six subjects to the placebo arm (2:1 randomization). One subject in the dapagliflozin-treated group did not complete the repeat euglycemic insulin clamp. Thus, this subject was included in the analysis of endogenous glucose production (EGP) only. Table 1 presents the baseline clinical, laboratory, and anthropometric characteristics that were similar in both groups.

Dapagliflozin caused a significant increase in urinary glucose excretion to $78 \pm 5 \mathrm{~g} / \mathrm{d}$ and $91 \pm 15 \mathrm{~g} / \mathrm{d}$ on days 2 and $3(P<0.0001)$ compared with days 0 and $1(8 \pm 1 \mathrm{~g} / \mathrm{d})$, and the glucosuria was 
Table 1

Clinical characteristics of study participants

\begin{tabular}{|c|c|c|}
\hline & Dapagliflozin & Placebo \\
\hline Subjects (no.) & 12 & 6 \\
\hline Age (yr) & $50 \pm 3$ & $54 \pm 3$ \\
\hline $\mathrm{BMI}\left(\mathrm{kg} / \mathrm{m}^{2}\right)$ & $31.4 \pm 1.8$ & $33.3 \pm 2.5$ \\
\hline Diabetes duration (yr) & $5.8 \pm 1.9$ & $7.5 \pm 4$ \\
\hline $\mathrm{HbA} 1 \mathrm{c}(\%)$ & $8.4 \pm 0.3$ & $8.8 \pm 0.9$ \\
\hline Fasting PG (mg/dl) & $165 \pm 9$ & $161 \pm 10$ \\
\hline Fasting FFA ( $\mu \mathrm{mol} / \mathrm{l})$ & $0.46 \pm 0.06$ & $0.50 \pm 0.07$ \\
\hline Fasting PI $(\mu \mathrm{U} / \mathrm{ml})$ & $7 \pm 1$ & $14 \pm 5$ \\
\hline \multicolumn{3}{|l|}{ Treatment } \\
\hline Met (no. subjects) & 9 & 4 \\
\hline Met + SU (no. subjects) & 3 & 2 \\
\hline
\end{tabular}

SU, sulfonylurea; Met, metformin; $\mathrm{PI}$, plasma insulin; $\mathrm{PG}$, plasma glucose.

maintained at day $14(75 \pm 5 \mathrm{~g} / \mathrm{d})$. In the placebo-treated group, the baseline urinary glucose excretion was $1 \pm 1 \mathrm{~g} / \mathrm{d}$ and did not change significantly on days 2,3 , and 14 . Body weight did not change significantly in the placebo-treated group $(-0.3 \pm 0.1 \mathrm{~kg})$ and declined modestly in the dapagliflozin-treated group $(-1.2 \pm 0.3 \mathrm{~kg})$.

Glucose disposal and EGP during insulin clamp. The fasting plasma glucose $(165 \pm 9 \mathrm{mg} / \mathrm{dl}$ and $167 \pm 9 \mathrm{mg} / \mathrm{dl})$ and plasma glucose concentration during the last hour of the insulin clamp $(98 \pm 1 \mathrm{mg} / \mathrm{dl}$ and $99 \pm 2 \mathrm{mg} / \mathrm{dl}$ ) were similar in the dapagliflozin-treated and placebo-treated groups, respectively. The fasting plasma insulin $(8 \pm 2 \mu \mathrm{U} / \mathrm{ml}$ and $12 \pm 4 \mu \mathrm{U} / \mathrm{ml})$ as well as the plasma insulin concentration during the last hour of the insulin clamp $(110 \pm 6 \mu \mathrm{U} / \mathrm{ml}$ and $122 \pm 5 \mu \mathrm{U} / \mathrm{ml}$ ) were similar in the dapagliflozin-treated and placebo-treated group, respectively.

At baseline, whole body insulin-stimulated glucose disposal during the insulin clamp was similar in subjects randomized to dapagliflozin or placebo $(4.3 \pm 0.4 \mathrm{mg} / \mathrm{kg} / \mathrm{min}$ vs. $4.0 \pm 0.5 \mathrm{mg} / \mathrm{kg} / \mathrm{min}$, $P=\mathrm{NS}$ ). Following 14 days of dapagliflozin treatment, whole body glucose disposal during the insulin clamp increased to $5.7 \pm 0.4 \mathrm{mg} / \mathrm{kg} / \mathrm{min}$ and remained unchanged in placebo-treated subjects $(4.2 \pm 0.5 \mathrm{mg} / \mathrm{kg} / \mathrm{min})(P<0.05$ vs. baseline and vs. placebo $)$ (Figure 1). During the insulin clamp, urinary glucose excretion was quantitated and subtracted from the rate of whole body glucose disposal to calculate insulin-stimulated tissue glucose disposal. After correction for urinary glucose loss, insulin-stimulated tissue glucose disposal remained elevated in dapagliflozin-treated subjects compared to baseline $(5.0 \pm 0.4 \mathrm{mg} / \mathrm{kg} / \mathrm{min}$ vs. $4.3 \pm 0.6 \mathrm{mg} / \mathrm{kg} / \mathrm{min}$, $P<0.05$ vs. baseline and placebo) (Figure 1 ).

At baseline, EGP was $2.0 \pm 0.1 \mathrm{mg} / \mathrm{kg} / \mathrm{min}$ and $2.1 \pm 0.1 \mathrm{mg} / \mathrm{kg} / \mathrm{min}$ in the placebo-treated and dapagliflozin-treated groups $(P=\mathrm{NS})$, respectively, and EGP was suppressed to $0.32 \pm 0.10 \mathrm{mg} / \mathrm{kg} / \mathrm{min}$ and $0.34 \pm 0.10 \mathrm{mg} / \mathrm{kg} / \mathrm{min}(P=\mathrm{NS})$ during the insulin clamp. During the insulin clamp performed on day 14 , basal EGP was $2.11 \pm 0.10 \mathrm{mg} / \mathrm{kg} / \mathrm{min}$ and $2.55 \pm 0.20 \mathrm{mg} / \mathrm{kg} / \mathrm{min}$ in the placebo-treated and dapagliflozin-treated groups $(P<0.05)$, respectively, and EGP was suppressed to $0.35 \pm 0.11 \mathrm{mg} / \mathrm{kg} / \mathrm{min}$ and $0.22 \pm 0.10 \mathrm{mg} / \mathrm{kg} / \mathrm{min}$ during the insulin clamp.

EGP following dapagliflozin and placebo. At baseline (day 1), the rate of basal EGP was similar in both groups (Figure 2). During the measurement of EGP on day 2, the plasma glucose concentration decreased similarly (by $37 \pm 15 \mathrm{mg} / \mathrm{dl}$ and $38 \pm 15 \mathrm{mg} / \mathrm{dl}$, respectively) from time 0 to 240 minutes in subjects receiving dapagliflozin and placebo (drug was administered at time 0 ) (Figure 3 ). In subjects receiving placebo, the rate of EGP continued to decrease progressively from $2.10 \pm 0.11 \mathrm{mg} / \mathrm{kg} / \mathrm{min}$ at baseline to $1.40 \pm 0.07 \mathrm{mg} / \mathrm{kg} / \mathrm{min}$ at the study's end $(P<0.001)$, and the decrement in EGP paralleled the decrement in fasting plasma glucose (FPG). In marked contrast, following dapagliflozin administration, EGP initially decreased slightly and then increased progressively thereafter (Figure 3). The rate of EGP during the last 40 minutes after dapagliflozin administration was above baseline $(2.30 \pm 0.13 \mathrm{mg} / \mathrm{kg} / \mathrm{min}$ vs. $2.16 \pm 0.11 \mathrm{mg} / \mathrm{kg} / \mathrm{min}, P=\mathrm{NS} ; P<0.05$ vs. placebo). The mean difference in EGP between dapagliflozin-treated and placebo-treated subjects $(0.76 \pm 0.10 \mathrm{mg} / \mathrm{kg} / \mathrm{min}$ or 16.6 grams over 4 hours, $P<0.05)$ virtually is identical to the amount of glucose excreted in the urine in dapagliflozin-treated subjects ( 15 grams). On day 3 , the plasma glucose concentration in dapagliflozin-treated subjects decreased by $23 \mathrm{mg} / \mathrm{dl}$ compared with that at day $1(P<0.05)$ and compared with a $5 \mathrm{mg} / \mathrm{dl}$ increase in subjects who received placebo $(P<0.05)$, while EGP increased by $17 \%(2.17 \pm 0.11 \mathrm{mg} / \mathrm{kg} / \mathrm{min}$ to $2.53 \pm 0.16 \mathrm{mg} / \mathrm{kg} / \mathrm{min}, P<0.05$ vs. baseline and vs. placebo) in dapagliflozin-treated subjects and remained unchanged in subjects who received placebo $(2.08 \pm 0.11 \mathrm{mg} / \mathrm{kg} / \mathrm{min}$ and $2.13 \pm 0.12 \mathrm{mg} / \mathrm{kg} / \mathrm{min}, P=\mathrm{NS}$ ) (Figure 2).

Plasma insulin and glucagon. The mean (measured on the day of the baseline insulin clamp and on days 1 and 2) fasting plasma insulin concentration was $7 \pm 1 \mu \mathrm{U} / \mathrm{ml}$ and $14 \pm 5 \mu \mathrm{U} / \mathrm{ml}$ in the dapagliflozin-treated and placebo-treated groups, respectively. The plasma insulin concentration decreased progressively in both dapagliflozin-treated and placebo-treated groups on day 2, i.e., the first day of dapagliflozin administration (Figure 3), reaching a mean of $5 \pm 1 \mu \mathrm{U} / \mathrm{ml}$ and $12 \pm 5 \mu \mathrm{U} / \mathrm{ml}$ after 240 minutes, but the decrease from baseline did not reach statistical significance in either group. On day 3 , the plasma insulin concentration decreased in the dapagliflozin-treated group $(4 \pm 1 \mu \mathrm{U} / \mathrm{ml}, P<0.05$ vs. baseline) and did not change in the placebo-treated group $(11 \pm 3 \mu \mathrm{U} / \mathrm{ml}, P=\mathrm{NS}$ vs. baseline) compared with that at day 1. Conversely, approximately 1 hour after dapagliflozin administration, at a time when the plasma glucose concentration had declined from $167 \mathrm{mg} / \mathrm{dl}$ to $153 \mathrm{mg} / \mathrm{dl}$, the plasma glucagon concentration increased progressively, reaching a peak of $79 \pm 8 \mathrm{pg} / \mathrm{ml}$ $(P<0.01$ vs. baseline and vs. placebo) after 240 minutes (Figure 3$)$, while it did not change significantly in placebo-treated subjects.
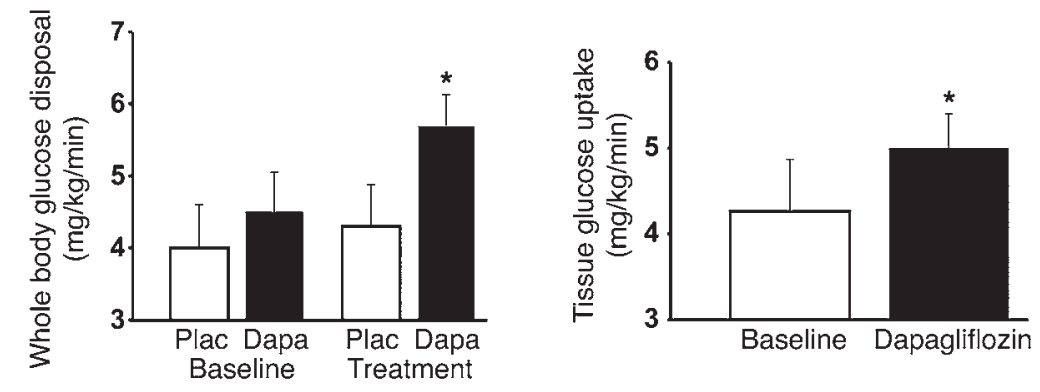

Figure 1

Whole body and tissue glucose disposal during the euglycemic insulin clamp studies performed in subjects with type 2 diabetes before (Baseline) and after 14 days of treatment with dapagliflozin (Dapa) or placebo (Plac). ${ }^{*} P<0.05$. 


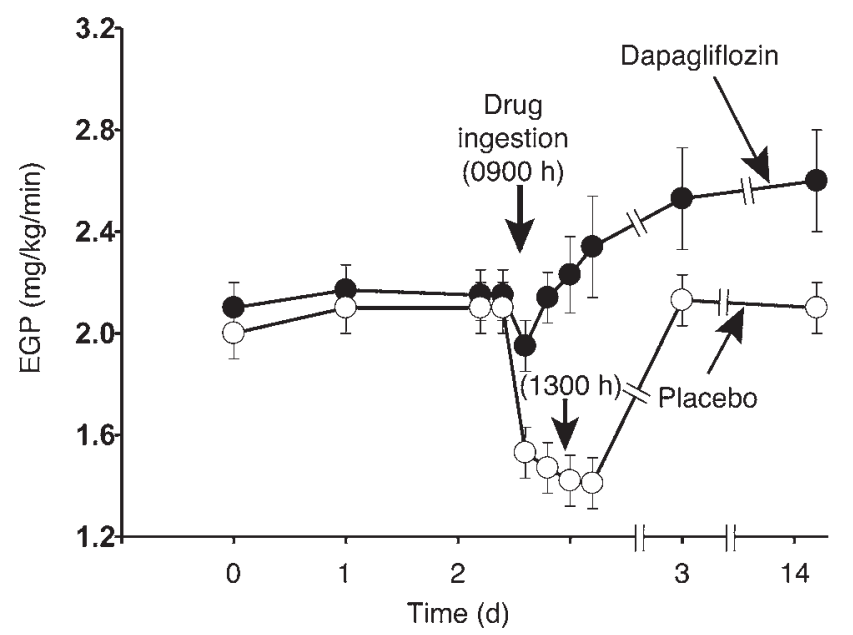

Figure 2

Basal EGP before and after ingestion of dapagliflozin or placebo EGP was measured on day 0 with the euglycemic clamp, on days 1 and 2 before subjects ingested dapagliflozin or placebo, and on days 2, 3, and 14 during dapagliflozin treatment. Note the break in the time scale ( $x$ axis) between days 2 and 3 and between days 3 and 14 .

On day 3 , the fasting plasma glucagon concentration was $32 \%$ higher than on day $1(85 \pm 7 \mathrm{pg} / \mathrm{ml}$ vs. $64 \pm 4 \mathrm{pg} / \mathrm{ml}, P<0.05$ vs. day 1 and vs. placebo on day 3 ) in dapagliflozin-treated subjects, while there was no significant change in plasma glucagon concentration in placebo-treated subjects.

On day 14, when the basal rate of EGP remained elevated, the fasting plasma glucagon concentration also remained significantly increased $(77 \pm 6 \mathrm{pg} / \mathrm{ml}, P<0.05)$ compared with baseline prior to dapagliflozin administration $(64 \pm 4 \mathrm{pg} / \mathrm{ml})$. The fasting plasma insulin concentration on day 14 was significantly $(P<0.05)$ decreased $(5 \pm 1 \mu \mathrm{U} / \mathrm{ml}$ vs. $7 \pm 1 \mu \mathrm{U} / \mathrm{ml})$ in the dapagliflozintreated group and did not change in the placebo-treated groups $(12 \pm 5 \mu \mathrm{U} / \mathrm{ml}$ vs. $14 \pm 5 \mu \mathrm{U} / \mathrm{ml})$. The glucagon/insulin ratio increased from $12 \pm 2$ to $20 \pm 3$ in the dapagliflozin-treated group $(P<0.01) 4$ hours after drug administration on day 2 and did not change in the placebo-treated group $(7 \pm 2$ to $9 \pm 2$, $P=$ NS). On days 3 and 14, the glucagon/insulin ratio in the dapagliflozin-treated group increased further to $28 \pm 7$ and $27 \pm 7$, respectively (both $P<0.01$ ). On days 3 and 14, the glucagon/insulin ratio in the placebo-treated group remained unchanged $(8 \pm 2$ and $8 \pm 2$, respectively) $(P=\mathrm{NS})$.

\section{Discussion}

The present results demonstrate that lowering the plasma glucose concentration by inducing glucosuria in individuals with T2DM significantly improves insulin-stimulated tissue glucose disposal. Both insulin-stimulated whole body glucose disposal and tissue glucose disposal (after subtracting urinary glucose loss) significantly improved following reduction of the plasma glucose concentration (by $37 \mathrm{mg} / \mathrm{dl}$ ) with 2 weeks of dapagliflozin treatment. The improvement in insulin sensitivity is consistent with previous observations from our group in rats (3). The most likely explanation for the increase in insulin-mediated tissue glucose disposal is the reduction in plasma glucose concentration, i.e., amelioration of glucotoxicity (2). It should be noted, however, that in the dapagliflozin-treated group there was a modest decrease in body weight $(-1.2 \mathrm{~kg}$ or $-2.6 \mathrm{lbs})$, which was not significantly different from the decrease in body weight observed in the placebo-treated group $(-0.3 \mathrm{~kg}$ or $-0.7 \mathrm{lbs})$. Therefore, it cannot be excluded that the modest reduction in body weight contributed in part to the improvement in insulin sensitivity. Since $>80 \%$ of insulin-mediated glucose disposal during the euglycemic insulin clamp takes place in skeletal muscle (16), these results indicate that lowering the plasma glucose concentration in T2DM significantly improves muscle insulin resistance and are consistent with a glucotoxic effect of chronic hyperglycemia to impair tissue insulin action in individuals with diabetes (2-9). Further, they demonstrate that the glucotoxic effect of chronic hyperglycemia on insulin resistance is reversible. Of note, dapagliflozin caused no significant change in the fasting plasma free fatty acid concentration.

The insulin infusion rate used during the insulin clamp in the present study was chosen to focus on the change in insulin sensitivity in muscle. Thus, an insulin-sensitizing effect in liver secondary to correction of chronic hyperglycemia cannot be excluded and would require a lower insulin infusion rate, closer to that which produces half-maximal suppression of hepatic glucose production (HGP). Last, our observations underscore the importance of achieving the recommended treatment glycemic goals in individuals with T2DM and demonstrate that restoring the normal plasma glucose concentration, not only decreases the risk of microvascular complications, but also improves one of the core metabolic defects in T2DM, i.e. insulin resistance in muscle.

Because of the close relationship between EGP (primarily reflects liver) and the fasting plasma glucose concentration (17), the decrease in FPG brought about by dapagliflozin would be expected to be associated with a decrease in HGP. Surprisingly, however, the present results demonstrate that lowering plasma glucose concentration by inhibiting sodium-glucose cotransporter 2 (SGLT2) in the kidney and inducing glucosuria is associated with a paradoxical increase in EGP (Figures 2 and 3). The mechanism via which glucosuria causes an increase in EGP is not clear. A decrease in FPG concentration potentially could lead to an increase in HGP, due to removal of the inhibitory effect of hyperglycemia on HGP $(18,19)$. However, plasma glucose concentration declined similarly in placebo-treated and dapagliflozin-treated individuals, while EGP increased only in the dapagliflozin-treated group (Figure 3). This observation indicates that the increase in EGP in dapagliflozin-treated individuals is independent of the decrease in plasma glucose concentration.

The increase in plasma glucagon concentration observed with dapagliflozin provides an obvious explanation for the increase in EGP. Glucagon is a powerful stimulator of HGP (18-20), and the $23 \%$ increase in plasma glucagon concentration is sufficient to explain the increase in HGP in dapagliflozin-treated subjects (20). Consistent with this scenario, an increase in plasma glucagon concentration was observed only in dapagliflozin-treated subjects and not in placebo-treated subjects, despite a similar decrease in plasma glucose concentration in both groups. Further, the time sequence of increase in plasma glucagon on day 2 closely paralleled the increase in EPG, and the increase in plasma glucagon persisted on days 3 and 14 in parallel with the increase in EGP in dapagliflozin-treated subjects (Figure 4). Of note, clinical trials with other SGLT2 inhibitors have reported an increase in plasma glucagon concentration despite a decrease in FPG concentration (21). Further, there was a small decrease in plasma insulin concentration on day 3 , which was sustained at day 14 . The increase in plasma 

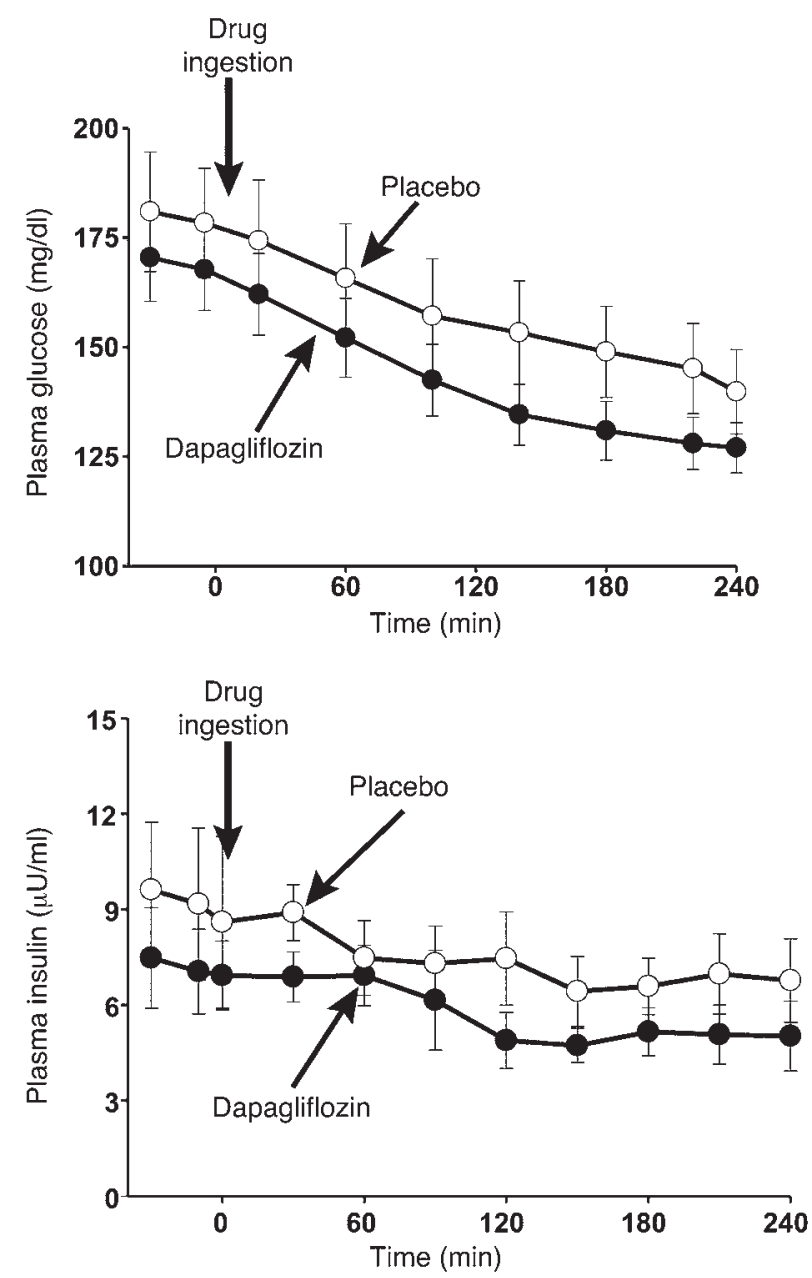
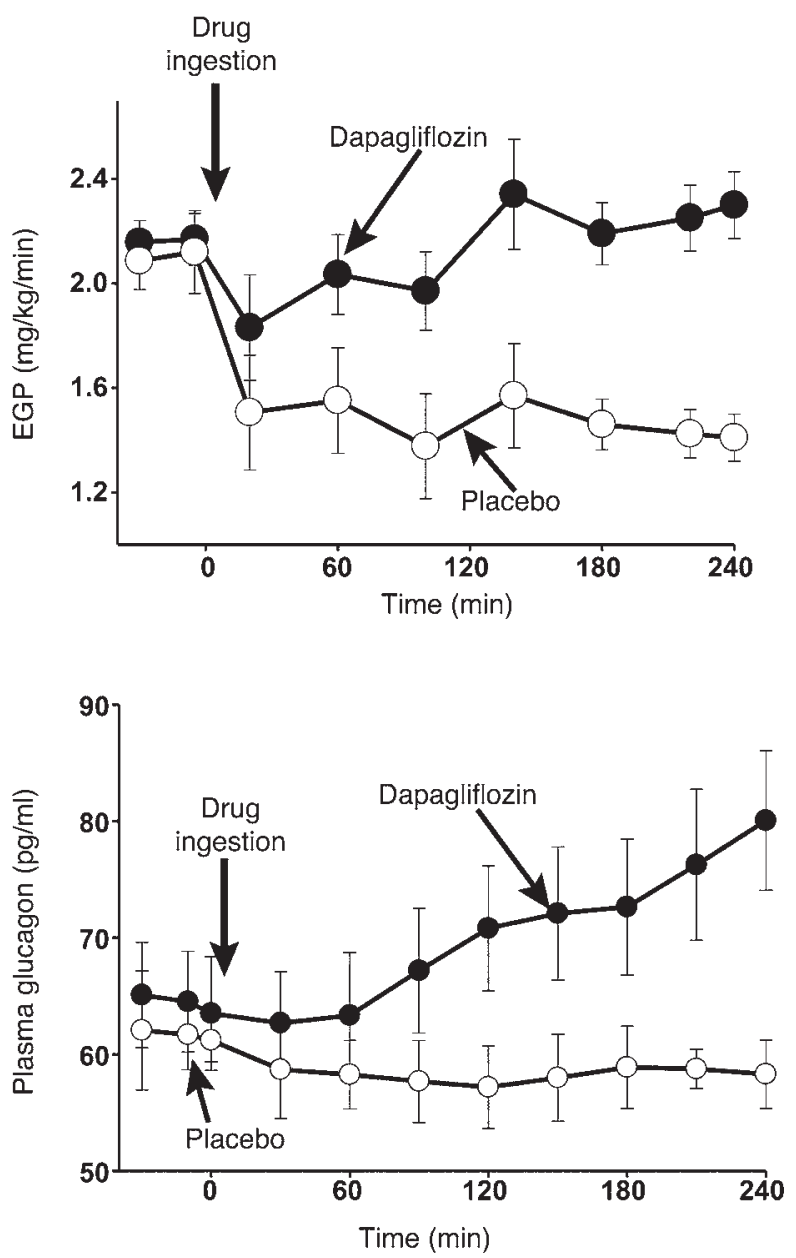

Figure 3

Plasma glucose, insulin, and glucagon concentrations and EGP in the study. On day 2, the ${ }^{3} \mathrm{H}$-glucose infusion was started 3 hours before drug ingestion (time 0 ) and continued for 4 hours after drug ingestion (see Methods for more details).

glucagon concentration, in the face of a decrease in plasma insulin concentration, led to a marked increase in the plasma glucagon/ insulin ratio, which is an important regulator of $\mathrm{HGP}(19)$.

Last, it is possible that the increase in EGP is not derived from the liver but from the kidney. It has been estimated that as much as $15 \%$ to $20 \%$ of basal EGP comes from the kidney $(22,23)$. However, the kidney does not respond to glucagon with an increase in glucose output (24). The close temporal relationship between the increase in plasma glucagon and the increase in EGP following dapagliflozin administration is most consistent with an effect on the liver, but does not exclude the kidney, as the organ responsible for the increase in EGP. Additional studies will be required to define the mechanism(s) via which dapagliflozin-induced glucosuria triggers the increase in glucagon secretion. We have shown previously that an acute decline in plasma glucose concentration (induced by insulin) from one hyperglycemic level to a lower, but still hyperglycemic, level in subjects with T2DM can stimulate the release of glucagon and other counter-regulatory hormones (25). It also is possible that the dapagliflozininduced glucosuria activates a neural reflex that connects the kidney directly with the pancreatic $\alpha$ cells or indirectly via activation of neuronal centers in the CNS that communicate with the $\alpha$ cells.
The increase in EGP following dapagliflozin treatment has important clinical implications. The increase in EGP $(0.36 \mathrm{mg} / \mathrm{kg} / \mathrm{min})$ on day 3 compared with that at day 1 in dapagliflozin-treated subjects resulted in the addition of approximately 47 grams of glucose per day to the systemic circulation. This amount of glucose ( 47 grams) approximates half of the amount of glucose $(\sim 91$ grams) excreted in the urine secondary to SGLT2 inhibition by dapagliflozin on day 3 . Thus, the increase in EGP in response to glucosuria offsets approximately half of the amount of glucosuria produced by inhibiting SGLT2. If the increase in EGP would have been prevented, the decrease in FPG caused by dapagliflozin would have been approximately double. It would be of great interest to examine combination therapy with SGLT2 inhibitor plus an incretin mimetic agent that inhibits glucagon and stimulates insulin secretion (26). These incretin-mediated actions would be anticipated to block the increase in EGP produced by the SGLT2 inhibitor and augment its glucose lowering ability. Based on these considerations, we postulate that combination therapy with SGLT2 inhibitor plus DPP-4 inhibitor or GLP-1 analog would exert an additive or even synergistic effect to lower plasma glucose concentration and $\mathrm{HbA} 1 \mathrm{c}$ in individuals with T2DM. 
Dapagliflozin-treated subjects
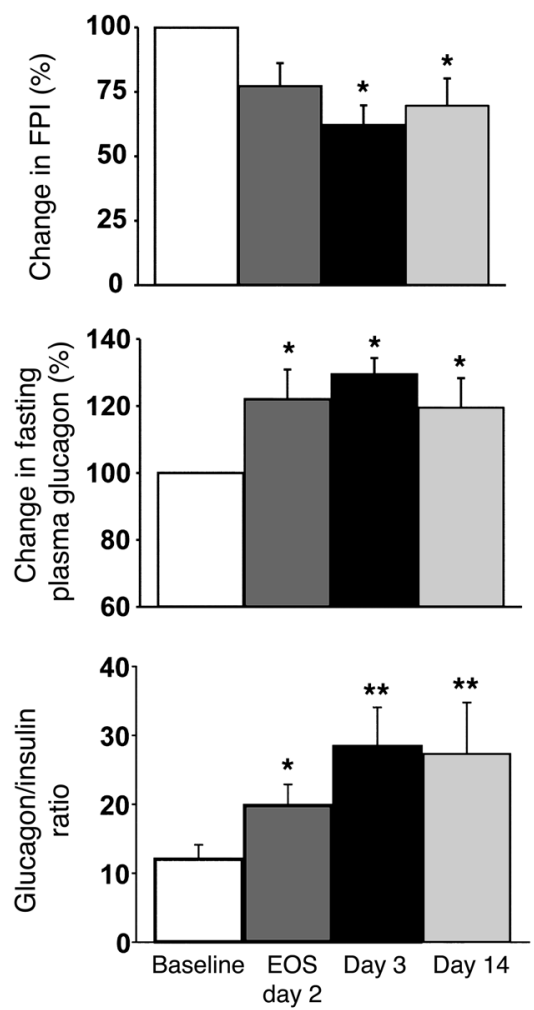

Placebo-treated subjects
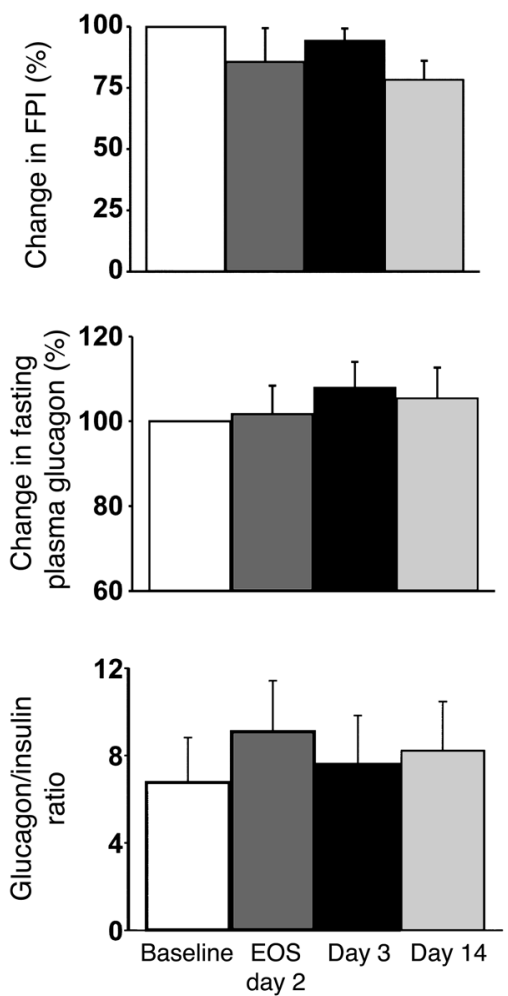

\section{Figure 4}

Change in the fasting plasma insulin and fasting plasma glucagon concentrations and the ratio between the fasting plasma glucagon to insulin concentrations after dapagliflozin and placebo administration relative to baseline. The baseline plasma insulin and glucagon concentrations represent the mean on the day of the baseline insulin clamp and on days 1 and 2 when HGP was measured. FPI, fasting plasma insulin; EOS, end of study. ${ }^{\star} P<0.05,{ }^{\star \star} P<0.01$.
The decrease in plasma glucose concentration during day 2 of the study (Figure 3 ) in subjects receiving placebo can be explained by the prolonged fasting period ( 20 hours). Consistent with this, the rate of EGP decreased significantly in subjects receiving placebo from $2.10 \pm 0.11 \mathrm{mg} / \mathrm{kg} / \mathrm{min}$ at baseline to $1.40 \pm 0.07 \mathrm{mg} / \mathrm{kg} / \mathrm{min}$ at study's end $(P<0.001)$. The mean difference in EGP between dapagliflozin-treated and placebo-treated subjects $(0.70 \pm 0.10 \mathrm{mg} / \mathrm{kg} / \mathrm{min})$ is virtually identical to the amount of glucose excreted in the urine during the study in dapagliflozintreated subjects ( 15 grams). Thus, the decrease in FPG in placebo-treated subjects was entirely accounted for by a decline in EGP, while the decline in FPG in dapagliflozin-treated subjects was entirely accounted for by renal glucose excretion.

In summary, the present results demonstrate that, in individuals with T2DM, the reduction in mean day-long plasma glucose concentration brought about by the glucosuric effect of dapagliflozin improves tissue sensitivity to insulin, providing strong evidence for the glucotoxicity hypothesis in humans. However, the decline in plasma glucose concentration following initiation of dapagliflozin therapy is blunted by an increase in EGP. This raises the interesting possibility of the existence of a novel reflex arc - either directly or neurally mediated between the kidney and the liver/pancreas.

\section{Methods}

Subjects. Eighteen men with T2DM treated with metformin $(n=13)$ or metformin plus sulfonylurea $(n=5)$ participated in the study. Other than diabetes, subjects were in general good health, as determined by medical history, physical exam, screening lab tests, urinalysis, and EKG. Table 1 summarizes the clinical characteristics of the study participants. Body weight was stable ( \pm 3 pounds) in all subjects for $\geq 3$ months prior to study, and no subject participated in any excessively heavy exercise program. No subjects were taking any medications known to affect glucose metabolism.

Research design. At baseline, all subjects received a 4-hour hyperinsulinemic euglycemic clamp with $3-{ }^{3} \mathrm{H}$-glucose to quantitate whole body insulinmediated glucose disposal and EGP following a 10-hour overnight fast (see below). Within 7 to 14 days after completing the insulin clamp, subjects were admitted to the Clinical Research Center for 3 days. Starting at 6:00 AM on day 1 , basal EGP was measured with $3-{ }^{3} \mathrm{H}$-glucose, which was administered as a prime $(25 \mu \mathrm{Ci} \times \mathrm{FPG} / 100)$ continuous $(0.25 \mu \mathrm{Ci} / \mathrm{min})$ infusion for 3 hours (6:00-9:00 AM). Blood samples for determination of plasma glucose, insulin, glucagon, and tritiated glucose radioactivity were obtained every 5 to 10 minutes during the last 30 minutes. At 6:00 AM on day 2, subjects received a $3-{ }^{3} \mathrm{H}$-glucose infusion as per day 1 , and the tritiated glucose infusion was continued for 7 hours. After a 3-hour equilibration period (9:00 AM) on day 2, subjects received dapagliflozin $(10 \mathrm{mg})$ or placebo in randomized double-blind fashion, and blood samples were drawn every 20 minutes for 4 hours after drug administration. At 6:00 AM on day 3, following a 10-hour overnight fast, subjects received a repeat tritiated glucose infusion as per day 2 and dapagliflozin $(10 \mathrm{mg})$ or placebo was ingested 3 hours after starting the tritiated glucose infusion, which was given for a total of 7 hours. 24-hour urinary collections for measurement of urinary glucose excretion were obtained on days $0,1,2$, and 3 . After day 3 , subjects continued to take dapagliflozin $(10 \mathrm{mg} / \mathrm{d})$ or placebo for an additional 12 days, and, on day 14, the euglycemic hyperinsulinemic clamp was repeated.

Euglycemic insulin clamp. Subjects remained fasting after 10:00 PM. At 6:00 AM on the following day a catheter was placed into an antecubital vein for the infusion of all test substances. A second catheter was inserted retrogradely into a vein on the dorsum of the hand, and the hand was placed into a thermoregulated box heated to $70^{\circ} \mathrm{C}$. At 6:00 $\mathrm{AM}$, a prime $(25 \mu \mathrm{Ci})$ continuous $(0.25 \mu \mathrm{Ci} / \mathrm{min})$ infusion of $3{ }^{-3} \mathrm{H}$-glucose (DuPont 
NEN Life Science Products) was started (as described above) and continued for 7 hours. After a 3-hour basal tracer equilibration period (9:00 AM), subjects received a prime continuous $\left(80 \mathrm{mU} / \mathrm{m}^{2} / \mathrm{min}\right)$ insulin infusion for 240 minutes (27). During the last 30 minutes of the basal equilibration period, plasma samples were taken at 5- to 10 -minute intervals for determination of plasma glucose and insulin concentrations and tritiated glucose radioactivity. During the insulin infusion, plasma glucose concentration was measured every 5 minutes. After the start of insulin, no glucose was infused until the plasma glucose concentration declined to $100 \mathrm{mg} / \mathrm{dl}$, at which level it was maintained by the adjustment of a variable glucose infusion based on the negative feedback principle (27). The plasma glucose concentration was maintained at approximately $100 \mathrm{mg} / \mathrm{dl}$, with a coefficient of variation $<5 \%$. Plasma samples were collected every 15 to 30 minutes from 0 to 180 minutes after the start of insulin and every 5 to 10 minutes from 180 to 240 minutes for the determination of plasma glucose and insulin concentrations and tritiated glucose-specific activity. Urine was collected from 0 to 240 minutes, and urinary volume and glucose concentration were measured. Urinary glucose loss was subtracted from the total rate of glucose disposal to determine insulin-mediated tissue glucose uptake.

Analytical techniques. Plasma glucose was measured by the glucose oxidase reaction (Glucose Oxidase Analyzer). Plasma insulin and glucagon concentrations were measured by a radioimmunoassay (Linco Research). Plasma $3-{ }^{3} \mathrm{H}$-glucose radioactivity was measured in Somogyi precipitates.

Statistics. Under steady-state postabsorptive conditions, the basal rate of endogenous glucose appearance $\left(R_{\mathrm{a}}\right)$ equals the $3{ }^{3} \mathrm{H}$-glucose infusion rate divided by steady-state plasma tritiated glucose-specific activity. After drug administration and during the insulin clamp, nonsteady-state conditions for $3{ }^{3} \mathrm{H}$-glucose-specific activity prevail and the rate of glucose appearance $\left(R_{\mathrm{a}}\right)$ was calculated with Steele's equation (28). The rate of residual
EGP during the insulin clamp was calculated by subtracting the exogenous glucose infusion rate from the tracer-derived $R_{\mathrm{a}}$. The insulin-stimulated rate of total body glucose disposal (TGD) was calculated by adding the rate of residual EGP to the exogenous glucose infusion rate. The rate of tissue glucose uptake was calculated by subtracting the rate of urinary glucose excretion during the insulin clamp from the TGD rate.

Values are expressed as mean \pm SEM. The difference between means of dapagliflozin-treated and placebo-treated groups (changes from baseline to day 14) was compared with repeated-measures ANOVA, with time and treatment groups as factors. Rates of TGD and EGP after dapagliflozin were compared to those before the start of dapagliflozin, with 2-sided paired $t$ test. Statistical significance was set at $P<0.05$.

Study approval. The study protocol was approved by the IRB of the University of Texas Health Science Center, San Antonio, and all subjects gave their written informed voluntary consent prior to participation.

\section{Acknowledgments}

This study was supported by NIH grant 5R01DK240923 (to R.A. DeFronzo). Bristol-Myers Squibb provided the dapagliflozin and matching placebo. The studies were carried out on the Bartter Clinical Research Unit of the South Texas Veterans Health Care System - Audie Murphy Division.

Received for publication April 29, 2013, and accepted in revised form November 14, 2013.

Address correspondence to: Ralph A. DeFronzo, Division of Diabetes, UTHSCSA, 7703 Floyd Curve Dr., San Antonio, Texas 78229, USA. Phone: 210.567.6691; Fax: 210.567.6554; E-mail: albarado@ uthscsa.edu.
1. He Z, King GL. Microvascular complications of diabetes. Endocrinol Metab Clin North Am. 2004; 33(1):215-238.

2. Rossetti L, Giaccari A, DeFronzo RA. Glucose toxicity. Diabetes Care. 1990;13(6):610-630.

3. Rossetti L, Smith D, Shulman GI, Papachristou D, DeFronzo RA. Correction of hyperglycemia with phlorizin normalizes tissue sensitivity to insulin. J Clin Invest. 1987;79(5):1510-1515.

4. Lindmark S, Burén J, Eriksson JW. Insulin resistance, endocrine function and adipokines in type 2 diabetes patients at different glycaemic levels: potential impact for glucotoxicity in vivo. Clin Endocrinol (Oxf). 2006;65(3):301-309.

5. Burén J, Lindmark S, Renström F, Eriksson JW. In vitro reversal of hyperglycemia normalizes insulin action in fat cells from type 2 diabetes patients: is cellular insulin resistance caused by glucotoxicity in vivo? Metabolism. 2003; 52(2):239-245.

6. Zierath JR, Galuska D, Nolte LA, Thörne A, Kristensen JS, Wallberg-Henriksson H. Effects of glycaemia on glucose transport in isolated skeletal muscle from patients with NIDDM: in vitro reversal of muscular insulin resistance. Diabetologia. 1994; 37(3):270-277.

7. Solomon TP, Knudsen SH, Karstoft K, Winding K, Holst JJ, Pedersen BK. Examining the effects of hyperglycemia on pancreatic endocrine function in humans: evidence for in vivo glucotoxicity. J Clin Endocrinol Metab. 2012;97(12):4682-4691.

8. Vourinen-Markkola H, Koivisto VA, Yki-Jarvinen $\mathrm{H}$. Mechanisms of hyperglycemia-induced insulin resistance in whole body and skeletal muscle of type I diabetic patients. Diabetes. 1992; 41(5):571-580.

9. Del Prato S, Leonetti F, Simonson DC, Sheehan P, Matsuda M, DeFronzo RA. Effect of sustained physiologic hyperinsulinemia and hyperglycaemia on insulin secretion and insulin sensitivity in man. Diabetologia. 1994;37(10):1025-1035.

10. Scarlett JA, Gray RS, Griffin J, Olefsky JM, Kolterman OG. Insulin treatment reverses the insulin resistance of type II diabetes mellitus. Diabetes Care. 1982;5(4):353-363.

11. Mayorov AY, Naumenkova IV, Antsiferov MB, Dedov II. Influence of insulin treatment on insulin sensitivity in insulin requiring type 2 diabetes patients. Diabetes Res Clin Pract. 2005;68(suppl 1):S54-S59.

12. Groop LC, et al. Glucose and free fatty acid metabolism in non-insulin-dependent diabetes mellitus. Evidence for multiple sites of insulin resistance. J Clin Invest. 1989;84(1):205-213.

13. Belfort R, et al. Dose-response effect of elevated plasma free fatty acid on insulin signaling. Diabetes. 2005;54(6):1640-1648.

14. Del Prato S, Leonetti F, Simonson DC, Sheehan P, Matsuda M, DeFronzo RA. Effect of sustained physiologic hyperinsulinaemia and hyperglycaemia on insulin secretion and insulin sensitivity in man. Diabetologia. 1994;37(10):1025-1035.

15. Abdul-Ghani MA, Norton L, DeFronzo RA. Role of sodium-glucose cotransporter 2 (SGLT 2) inhibitors in the treatment of type 2 diabetes. Endocr Rev. 2011;32(4):515-531.

16. DeFronzo RA, Jacot E, Jequier E, Maeder E, Wahren J, Felber JP. The effect of insulin on the disposal of intravenous glucose: results from indirect calorimetry and hepatic and femoral venous catheterization. Diabetes. 1981;30(12):1000-1007.

17. DeFronzo RA, Ferrannini E, Simonson DC. Fasting hyperglycemia in non-insulin dependent diabetes mellitus: contributions of excessive hepatic glucose production and impaired tissue glucose uptake. Metabolism. 1989;38(4):387-395.

18. DeFronzo RA, Ferrannini E. Regulation of hepatic glucose metabolism in humans. Diabetes Metab Rev. 1987;3(2):415-460.

19. Cherrington AD. Banting Lecture 1997. Control of glucose uptake and release by the liver in vivo. Diabetes. 1999;48(5):1198-1214.

20. Matsuda M, et al. Glucagon dose-response curve for hepatic glucose production and glucose disposal in type 2 diabetic patients and normal individuals. Metabolism. 2002;51(9):1111-1119.

21. Zambrowicz B, et al. LX4211, a dual SGLT1/SGLT2 inhibitor, improved glycemic control in patients with type 2 diabetes in a randomized, placebo-controlled trial. Clin Pharmacol Ther. 2012;92(2):158-169.

22. Meyer C, Gerich JE. Role of the kidney in hyperglycemia in type 2 diabetes. Curr Diab Rep. 2002; 2(3):237-241.

23. Cersosimo E, Garlick P, Ferretti J. Insulin regulation of renal glucose metabolism in humans. Am J Physiol. 1999;276(1 pt 1):E78-E84.

24. Gustavson SM, et al. Effects of hyperglycemia, glucagon, and epinephrine on renal glucose release in the conscious dog. Metabolism. 2004;53(7):933-941.

25. DeFronzo RA, Andres R, Bledsoe TA, Boden G, Faloona GA, Tobin JD. A test in man of the hypothesis that the rate of fall in glucose concentration triggers counter-regulatory hormonal response. Diabetes. 1977;26(5):445-452.

26. Edgerton DS, Johnson KM, Cherrington AD. Current strategies for the inhibition of hepatic glucose production in type 2 diabetes. Front Biosci. 2009; 14:1169-1181.

27. DeFronzo RA, Tobin JD, Andres R. Glucose clamp technique. A method for quantifying insulin secretion and resistance. Am J Physiol. 1979;237(3):E214-E223.

28. Steele R, Wall JS, De Bodo RC, Altszuler N. Measurement of size and turnover rate of body glucose pool by the isotope dilution method. Am J Physiol. 1956; 187(1):15-24 